\title{
A Vertical Peer Mentorship Model to Promote Early Career Academic Development: Implementation and Initial Outcomes
}

Ann F. Haynos, Ph.D. ${ }^{1}$; Kathryn A. Coniglio, M.S. ${ }^{2}$; Helen Burton Murray, Ph.D. ${ }^{3}$; Linsey Utzinger, Psy.D. ${ }^{4}$; Andrea B. Goldschmidt, Ph.D. ${ }^{5}$

${ }^{1}$ Department of Psychiatry and Behavioral Sciences, University of Minnesota, Minneapolis, MN

${ }^{2}$ Department of Psychology, Rutgers, The State University of New Jersey, Piscataway, NJ

${ }^{3}$ Department of Medicine, Massachusetts General Hospital, Boston, MA

${ }^{4}$ Melrose Center, Minneapolis, $\mathrm{MN}$

${ }^{5}$ Department of Psychiatry, University of Pittsburgh, Pittsburgh, PA

Correspondence: Ann F. Haynos, Ph.D., Department of Psychiatry, University of Minnesota, 2450 Riverside Ave., F253, Minneapolis, MN 55454. Email: afhaynos@umn.edu; Phone: 612273-9822; Fax: 612-273-9779

Ann Haynos, Ph.D., is an Assistant Professor in the Department of Psychiatry and Behavioral Sciences at the University of Minnesota and the Director of Research Operations for the Minnesota Center for Eating Disorders Research. She completed her Ph.D. in Clinical Psychology from the University of Nevada, Reno, predoctoral internship at Duke University Medical Center, and postdoctoral fellowship at the University of Minnesota. Dr. Haynos has served in a number of leadership roles supporting the mentorship and professional development of early career scholars, most notably co-chair of the Early Career Special Interest Group 
through the Academy for Eating Disorders (2017-2020). Dr. Haynos' research focuses on identifying and intervening upon the decision-making mechanisms of eating disorders.

Kathryn Coniglio, M.S., is a Ph.D. candidate in Clinical Psychology at Rutgers University. She has served as co-chair of the Early Career Special Interest Group through the Academy for Eating Disorders since 2017. Her research interests include pathological exercise and positive emotion dysregulation in low-weight eating disorders.

Helen Burton Murray, Ph.D. is a Clinical and Research Fellow in the Department of Medicine at the Massachusetts General Hospital/Harvard Medical School. She completed her Ph.D. in Clinical Psychology from the Drexel University and her predoctoral internship at Massachusetts General Hospital/Harvard Medical School. Dr. Burton Murray has served in several leadership roles aimed at supporting the education and development of early career scholars, including her current role as the Membership Committee co-chair of the Rome Psychogastroenterology Section and her tenure on the Early Career Special Interest Group through the Academy for Eating Disorders (2015-2018). Dr. Burton Murray's research focuses on the shared maintenance mechanisms between eating disorders and gastrointestinal conditions.

Linsey Utzinger, Psy.D., is a clinical psychologist at Park Nicollet's Melrose Center in Minneapolis, MN, where she specializes in evidence-based treatments for eating disorders across the lifespan. She completed her doctoral training in the PGSP-Stanford Consortium, predoctoral internship at Children's Hospital Colorado, and a T32 postdoctoral fellowship with the Midwest Regional Postdoctoral Training Grant in Eating Disorders Research. Recent leadership and 
mentorship roles have included her former position as a Clinical Assistant Professor in the Department of Psychiatry and Behavioral Sciences at Stanford University and serving as an elected co-chair of the Early Career Special Interest Group through the Academy for Eating Disorders (2015-2018).

Andrea Goldschmidt, Ph.D. is a Visiting Associate Professor of Psychiatry in the Department of Psychiatry at the University of Pittsburgh. She completed her Ph.D. in Clinical Psychology from Washington University, her predoctoral internship at the University of Missouri Counseling Center, and her postdoctoral fellowship at the University of Chicago. Dr. Goldschmidt was previously an Associate Professor (Research) in the Department of Psychiatry and Human Behavior at Brown Medical School and a Research Scientist at the Weight Control \& Diabetes Research Center within the Miriam Hospital. She has been a site PI and mentor on several NIHfunded T32 grants, and led the development of a vertical peer mentorship program as past cochair of the Academy for Eating Disorders New Investigators Special Interest Group (20142017). Her research focuses on the etiology and maintenance of dysregulated eating behaviors in children and adolescents with overweight/obesity.

Manuscript Word Count: 4730

Abstract Word Count: 149 


\begin{abstract}
Mentorship is critical for early career success. However, many barriers to mentorship exist, including inadequate supply of advanced mentors, inconsistent mentorship quality, and diverse mentorship needs. Additionally, few training experiences provide an opportunity to learn effective mentorship techniques. Vertical peer mentorship programs provide one solution to these pitfalls; slightly more advanced early career professionals (e.g., post-doctoral fellows) provide mentorship to more junior colleagues (e.g., graduate students), permitting mentorship and mentorship training in one dyad. Here, we detail the process of developing and refining an early career vertical peer mentorship program within a subspecialty of psychology. Initial evaluation data the first four years of the program ( $n=109$ respondents) indicate that the program was highly acceptable $(M=8.22, S D=4.25$ on a 10 -point scale) and productive (producing $\geq 25$ manuscripts published or under review and $\geq 21$ conference abstracts) during that time. This manuscript provides one model for developing a successful vertical peer mentorship program.
\end{abstract}

Keywords: mentorship; training; education 


\section{A Vertical Peer Mentorship Model to Promote Early Career Academic Development: Implementation and Initial Outcomes}

Academic mentors within the behavioral sciences serve a range of important functions for early career trainees, including professional advisement, knowledge facilitation, collaboration, support, role-modeling, and assistance with networking (Gruber et al., 2020). There are clear benefits of mentorship for mentees, including subjective outcomes (e.g., higher career satisfaction, self-efficacy), as well as objective outcomes (e.g., greater career achievement and advancement, compensation and funding, top-tier publications; Allen et al., 2004; Blau et al., 2010; Gruber et al., 2020; Efstathiou et al., 2018). Mentors also benefit from providing mentorship. One meta-analysis found that mentorship was associated with enhanced professional satisfaction, performance, and success for mentors across disciplines (Ghosha \& Reio Jr., 2013), resulting from fulfillment, refinement of leadership abilities, enhanced professional recognition, and mentee productivity (Burgess et al. 2018). The positive outcomes of mentorship can be longlasting (Callahan \& Watkins, 2018; Mallinckrodt \& Gelso, 2002) and multi-generational, as individuals who have received high-quality mentorship are more likely to mentor themselves (McBride et al., 2019).

The dominant academic mentorship model is that of one-on-one structured advisement of an early career mentee (e.g., graduate student) by a far more senior individual (e.g., faculty). This type of mentorship is considered beneficial (Jackson et al., 2003), but it comes with limitations. The most obvious drawback to this model is that of supply and demand. There are often far more people interested in mentorship from senior researchers than there are available mentors (Gruber et al., 2020; Jackson et al., 2003). Although advisement is typically mandated in graduate programs, many graduate students report having no formal mentorship and, among those who do, 
approximately $25 \%$ desire more access to their mentor's time (Clark et al., 2000). Limited mentor availability may result from the high professional demands placed on faculty coupled with low institutional support (i.e., financial and promotion incentives) for educational activities (Lundgren \& Orsillo, 2012). Ongoing one-on-one mentorship is frequently unavailable at other key career development stages, such as during undergraduate or early assistant professor years, which are critical periods for academic enrollment and retention (Gruber et al., 2020; Kupfer et al., 2009). Problems of access are especially pronounced for under-represented groups, such as women and sociocultural minority groups (Girves et al., 2005), even though these groups benefit more from mentorship than individuals in the majority (Fleming et al., 2005). Thus, it would be beneficial to increase the number of willing individuals to provide mentorship to professionals at a variety of early career stages.

A second pitfall of the dominant mentorship model pertains to a reliance on a single individual to meet all professional needs. Trainees are expected to develop: (1) a variety of research skills, including increasingly complex and evolving study designs, methods, and analyses; (2) professional development skills (e.g., time management, communication skills); (3) an impressive portfolio of work products (e.g., manuscripts, grant funding); and (4) for clinical disciplines within the behavioral sciences, clinical acumen and treatment proficiency of sufficient depth and breadth to serve as general or specialized provider. It is unlikely that one mentor can adequately advise on all of these needs (Gruber et al., 2020). Indeed, given the fast pace of methodological advances (Thimbleby, 2013), it is exceedingly difficult for faculty to remain up to date on all skills that trainees may wish to develop. At times, several decades separating the mentee and mentor may mean that a mentor's advice is outdated. Other times, the multiple roles that are held by the primary supervisor come into conflict (e.g., when mentee is 
also a paid employee on a grant). There are also transitional periods in which it is appropriate for mentees to establish autonomy from a primary advisor to launch career independence (e.g., postdoctoral fellowship), despite still needing professional support. For these reasons, there are merits to having multiple mentors.

Finally, sometimes mentorship matches are not ideal. Despite evidence that mentorship quality varies considerably (Forehand, 2008), there is minimal explicit training in academic mentorship skills. Thus, many advisors feel inadequately prepared to meet their mentees' needs (Gruber et al. 2020). Unfortunately, some mentees report negative mentorship experiences in which they perceive their mentor to be incompetent, neglectful, or abusive (Eby et al., 2000). Even among generally effective mentors, an interpersonal mismatch may occur due to graduate admission decisions being heavily weighted on applicant talent and research interest, rather than work and interactional style match with a prospective advisor (Gruber et al., 2020). In these situations, another mentoring experience outside of a primary advisor relationship is advisable. Peer mentorship is a potential mechanism by which many of these limitations can be overcome. Compared to a more hierarchical model, peer mentorship permits greater comfort and security (especially for sharing unformed ideas or learning inchoate skills), validation, support, and role-modeling from individuals currently or recently facing similar career-stage challenges (Andersen \& Watkins, 2018; Irvine et al., 2018). Within this model, peer mentors also enhance their mentorship capacities and benefit from learning in areas in which their mentee has greater expertise (Andersen \& Watkins, 2018). The few existing studies on peer mentorship in clinical professions demonstrate that it can yield a variety of positive outcomes, including decreased stress, anxiety, and isolation, and increased academic adjustment, performance, and retention for mentees, as well as increased skill and confidence building for mentors (Akinla et al., 2018; 
Asgari \& Carter, Jr 2016; Hamrin et al., 2006; Mikkonen et al., 2016). The primary barrier to peer mentorship is a perceived or actual lack of skill on the part of unseasoned mentors (Andersen \& Watkins, 2018; Benè \& Bergus, 2014). Therefore, a vertical "near-peer" model is often recommended, in which an individual is mentored by someone at a similar career stage, but slightly further advanced (Akinla et al., 2018; Irvine et al., 2018). There are limited data on the effects of peer mentorship programs, especially within psychology, and even less information about how to successfully structure such a program.

We will provide a model of an early career vertical peer mentorship program developed by one professional organization (the Early Career Special Interest Group [SIG] of the Academy for Eating Disorders [AED]) including initial program evaluation outcomes related to acceptability and efficacy. Although the eating disorders field is one area of clinical science that may benefit from additional of support for its early career members (Keel \& Smith, 2017), the aforementioned barriers to high quality mentorship are ubiquitous across the behavioral sciences. Thus, we describe the development, refinement, and evaluation of our program as a prototype for developing successful peer mentorship programs more broadly within other professional organizations or systems in the behavioral sciences.

\section{Program Origins and Development}

The development of the vertical peer mentorship program was borne from informal discussions among members of the Early Career SIG, a group of junior professionals ranging from undergraduates to assistant professors that participate in the AED professional organization. Many SIG members reported having limited access to mentors, datasets, or training experiences relevant to their area of interest. When this issue was raised with organization leadership, they indicated that later-stage researchers were already overburdened with mentorship demands in 
their formal advising and teaching roles and unable to accommodate additional mentees. In response to these challenges, SIG co-chairs developed a vertical mentorship program that involved having advanced early career professionals (e.g., postdoctoral fellows, assistant professors) serve as peer mentors to less advanced trainees (e.g., undergraduates, postbaccalaureates, early graduate students). The expectation was that, relative to more senior researchers, early career professionals may: 1) be more eager to engage in such a program in order to share data and develop collaborations; and 2) gain more professional development experience from providing mentorship (e.g., abstracts or manuscripts to add to their tenure dossier). The mentorship relationship was design to focus on a range of general early career issues, including advisement on specific career tasks (e.g., applying for postdoctoral fellowships), work/life balance, interpersonal issues and conflicts relevant to one's career trajectory, and the potential for collaborations within mentorship dyads.

\section{Mentorship Program Structure}

The vertical peer mentorship program described herein was piloted in 2016 and has continued to be offered annually. The program was developed and improved through an ongoing, iterative process involving significant feedback from Early Career SIG members. Below, we outline the current structure of the program, as well as key decision points that influenced the development of different formats and policies.

\section{Creation of Mentorship Dyads}

Annually, a notice is sent to the Early Career SIG AED listserv to solicit interest in participating in the mentorship program. To enter the program, all individuals interested in serving as mentee or mentor complete a survey to facilitate the creation of peer mentorship pairs. There is no limit to the number of times an individual can participate in the program; however, 
mentorship dyads are modified each year to ensure a diversity of mentorship experiences for early career professionals. Further, individuals can participate in the program as both a mentor and a mentee (i.e., in two separate dyads) if desired. As the mentorship program has grown in popularity, the sophistication with which matches are created has developed in tandem. See Appendices A and B for examples of the mentee and mentor surveys, respectively.

Once all matching survey data have been collected, a two- to three- hour meeting is held in which the chairs of the committee (two to four individuals) create mentorship matches. The goal of the matches is to balance the goals, research interests, and career stages of prospective mentors and mentees. Mentee participation traditionally has been heavily weighted towards graduate students, with fewer individuals in earlier (e.g., undergraduate, post-baccalaureate) or later (e.g., postdoctoral, assistant professor) stages seeking mentorship through this program. Therefore, the matching process typically begins at the tails of the early career distribution by attempting to identify appropriate, slightly more advanced mentors for participants at less represented career phases (e.g., early graduate student mentors for post-baccalaureate mentees, or assistant professor mentors for postdoctoral mentees). Subsequently, attempts are made to find a mentor at a more advanced career stage who is suited to fulfill the most highly ranked qualities designated by mentees. Matches based on shared research interests are prioritized, even when this is not explicitly emphasized by the mentees, as this practice has been found to foster greater ongoing collaboration. However, close pairing by interest proves difficult in cases in which research interests are highly specific or narrow. If a mentor from a particular country is desired, this is accommodated when possible.

\section{Initiation Strategies for Ensuring Dyad Success}


Scaffolding Initial Contact. Mentors and mentees are introduced via a personalized email that includes a verbal description of the reasoning behind their match and, in more recent years, the mentor's and mentee's responses to their respective matching surveys. Mentees are encouraged to contact their mentors within one week of receipt of this initial email to facilitate the mentee in taking initiative in establishing an active relationship. Follow-up emails are sent to each mentorship pair after one month with a general inquiry about how the relationship is proceeding. These safeguards ensure that initial matches are followed by early and regular contact, thus promoting a positive and productive mentorship relationship.

Provision of Mentorship Resources. No formal training is required for mentors in this program. However, a variety of written resources are shared online that can be optionally utilized to guide the mentorship relationship. These resources include descriptive, didactic articles on how to be an effective mentee (Zerzan et al., 2009) and mentor (Bardone-Cone, 2018; Lee, Dennis, \& Campbell, 2007) and practical templates for structuring the relationship, such as individual development plans for goal planning and mentorship agreement contracts to establish mutual mentorship expectations (e.g., focus, frequency, modality). The purpose of these resources has been to ensure that mentors feel adequately prepared for their role, mentees are empowered to actively participate in this relationship, and the mentorship dyad engages in mentorship that is efficient and focused.

\section{Organization and Activities of Mentorship Dyads}

Mentorship dyads are given significant flexibility in structuring the mentorship relationship based on their shared goals and preferences. Dyads are advised that regular contact would be most beneficial, but the pairs have autonomy in determining the frequency (i.e., weekly, monthly) and format (i.e., phone, video) of this contact. Contact between dyads has 
largely varied as a function of the goals of mentorship. For instance, mentees seeking guidance on a grant application may have frequent, but time limited contact with their mentors leading up to the deadline. Alternatively, mentees looking for more general professional development guidance may opt to schedule regular, comprehensive check-ins. Some dyads use mutuallyattended conferences as an opportunity for in-person meet-ups. In an effort to promote in-person contact with mentorship pairs, and networking with others in their respective professional circles, informal early career social events subsequently have been built into the annual conferences.

\section{Collection of Program Evaluation Data}

At the end of each year of the program, feedback surveys (see Appendix C) are sent to all participants (i.e., both mentees and mentors). Participants are queried about the frequency, structure, and goals of mentorship, and satisfaction with the pairing and the program through both quantitative and qualitative feedback. In a separate survey, participants are queried about any resulting work products (e.g., papers, conference presentations), either completed or in progress, that came out of the mentorship relationship. These data are reviewed and, where possible, remedies are incorporated in response to feedback in the following round of matches. Typically, the results of the survey are shared within the committee at the annual conference meeting to promote discussion about how to continuously improve the program.

\section{Troubleshooting Problems and Critiques}

Through the program implementation and feedback from members, various pitfalls and areas for improvement have emerged and the program has adapted to address these issues.

Imbalanced Numbers of Mentors and Mentees. Predictably, an uneven number of mentees and mentors sign up for the program each year. When there have been more mentors than mentees, mentors who did not represent an ideal match for any of the prospective mentees 
have been asked if they would be willing to be placed on a mentor waitlist in the case that a new pairing needs to be made. When there have been more mentees than mentors, which has more often been the case, mentors have been sometimes asked whether they would be willing to be paired with more than one mentee, or other appropriate colleagues who had not initially signed up for the program were personally contacted to find a match.

Failure to Initiate the Mentorship Relationship. In the first year of the program, many mentees never made initial contact with their designated mentor. This prompted the practice of having the SIG chairs follow up with dyads one month after matches were made to ensure contact early within the relationship. In the current iteration of the program, when the chairs discover that no contact has been made by the mentee, they send an email to determine whether the mentee remains interested in the program. If a mentee is no longer interested or does not respond, a new match (e.g., with a prospective mentee who missed the sign-up deadline) is made for the mentor or the mentor is placed on the mentor waitlist in case an issue arises in another dyad. Since institution of these policies, it has become less common for a mentee to not contact their designated mentor (e.g., in the 2019-2020 program, only two out of fifteen mentors indicated they did not hear from their mentee).

Dissatisfaction in Initial Matching. The most common form of critical feedback from participants has had to do with a perceived mismatch between mentor and mentee expectations, skills, interests, or knowledge. Infrequently, this mismatch has been perceived at the point of initial pairing, typically due to the mentee's perception that the mentor was not sufficiently senior. In these cases, first attempts have been made to troubleshoot ways to preserve the match (e.g., focusing mentorship on areas in which the mentor was more advanced). When this was not successful, other colleagues have been solicited to serve as an alternate mentor. In subsequent 
years, in the introductory email, participants have been encouraged to proceed with openness and flexibility, since it is not possible to match on all individual preferences. Feedback like this also led to the addition of querying mentorship seniority preference (see item 11 on Appendix A).

Dissatisfaction with Mentorship Relationship. A more common scenario has been that mentorship dyads are satisfied with the initial match, but discover over the course of working together that their work styles or goals for the relationship are not in sync. In some cases, mentees have indicated that they were looking for mentorship in an area in which few mentors had expertise (e.g., neuroimaging). Because it is not always possible to match in this program according to more specialized interests, a collaboration directory for the SIG was created as an offshoot of the formal mentorship program. In this directory, individuals indicate their current position, research interests, and grants/positions to which they have applied previously (i.e., and thus might be able to provide insight about). Subsequently, when a mentee has desired expertise in a niche area, they have been referred to the collaboration directory, in addition to being matched to a mentor who was otherwise an appropriate fit. Further, to enhance the quality of the matches, several additional questions have been added to the initial survey. Specifically, questions inquiring about mentees' preferences for the country and work style of mentor were added in response to feedback about the areas in which mentorship dyads were sometimes mismatched. In addition, individuals participating in the program have been encouraged to reach out to the organizers of this mentorship program early if they perceived there to be problems within the match to permit proactive interventions.

Difficulty Organizing the Mentorship Relationship. Initially, many individuals who were new to mentoring reported that they felt unclear about how to establish and facilitate an effective mentorship relationship. This encouraged the practice of providing optional materials 
for designing and structuring the mentorship relationship for those who needed further guidance (See Provision of Mentorship Resources above).

\section{Initial Program Evaluation Results}

Evaluations were completed by 109 program participants (53 mentees, 56 mentors) from an initial pool of 164 participants (82 mentorship dyads) over four initial years of the program, constituting a $66.5 \%$ response rate. In the pilot year (2016-2017), fewer evaluation questions were asked, therefore full data are only available on 80 participants (41 mentors, 39 mentees). Results are described in Table 1.

\section{Structure and Function of Mentoring Relationships}

The program was designed to permit flexibility of mentorship structure and goals, and program evaluation data suggest that these varied across dyads, with most common goals pertaining to general professional development (77.5\%), professional applications (e.g., for graduate school; $47.5 \%$ ), or manuscript writing (26.3\%). Approximately one-third of participants worked on a concrete product (e.g., paper) within their dyad. Average frequency of contact was slightly more than ever other month, though the range was considerable. One third of mentors $(33.3 \%)$ and about one quarter (26.1\%) of mentees endorsed having used the online mentorship resources. Those who utilized these resources $(n=16)$ reported high satisfaction with the materials $(M=8.88, S D=0.99$ on a 10 -point Likert scale $)$.

\section{Acceptability}

As highlighted in Table 1, the mentorship program has been highly acceptable to both mentees and mentors. Modal satisfaction rating response for all satisfaction items was 10, indicating the highest level of satisfaction. Further, most mentors and mentees reported plans for continued contact and collaboration after the formal program ended. Figure 1 visualizes the 
qualitative feedback on mentor and mentee satisfaction. Qualitative responses indicated that mentees appreciated the opportunity to network, enhance professional skills, and to foster a professional relationship outside of their institution. Mentors expressed appreciation for the professionalism, initiative, and proactivity of their mentees, as well as the opportunity to hone their mentorship skills and collaborate on work products. Among mentors and mentees, qualitative responses linked satisfaction to a good match between research interests and skills and dissatisfaction to mismatched expectations or poor responsivity of either party.

\section{Mentorship Byproducts}

Creation of specific work byproducts (e.g., manuscripts, grants) was not a requirement of the program or a stated goal for most dyads. Nonetheless, program participants have been highly productive. In the first four years of the program, mentorship dyads produced 18 peer-reviewed manuscript publications, with an additional 7 under review and 13 in preparation, 21 conference presentations, 8 grant applications (e.g., National Science Foundation, National Institute of Health F31/K23), and 15 applications to professional positions (e.g., graduate school, postdoctoral fellowships). This list is not exhaustive. Dyads volunteered information on their byproducts if desired, but it is possible that a greater number of work products exist among dyads that did not respond to program evaluations or chose not to publicize their products.

\section{Discussion}

In this manuscript, we describe the iterative development of an early career vertical peer mentorship program conducted within a clinical field of the behavioral sciences in hopes of inspiring other professional organizations to do the same. In the first four years of the program, it was reported as highly acceptable to both mentees and mentors and the collaborative relationships were found to be productive. Given the feasibility and initial success of this 
program, we believe it has the potential to serve as a model for other early career peer mentorship programs in the psychology and we encourage further testing of this model. The results of this program highlight that satisfying, impactful mentorship can be delivered by individuals who are relatively early in their professional trajectory. This point is especially important given the barriers to accessing effective mentorship in the current academic landscape (Gruber et al., 2020). While there has been an increase in individuals seeking advanced degrees (U.S. Census Bureau, 2018), faculty positions have dwindled (Kahn \& Ginther, 2017) and the demands on faculty have grown (Lundgren \& Orsillo, 2012), leaving a gap in time and resources to meet the demand of mentoring the emerging scientific workforce. Simultaneously, the behavioral sciences have grown more complex and it has become increasingly difficult to obtain grant funding (Kahn \& Ginther, 2017) or to publish high-visibility research (Li et al.,). These influences conspire to inflate the need for guidance of early career professionals. In subspecialties in which high-impact publication and funding opportunities are even further restricted, the need for enhanced support, connections, and resources towards developing strong early career researchers may be even more keenly felt (Murray et al., 2017; Strand \& Bulik, 2018).

Vertical peer mentorship provides multiple solutions towards narrowing this mentorship gap. First, this model can permit early career individuals to access mentorship that would otherwise be unavailable. In addition to providing an opportunity to connect to an early career mentor, mentees also often experienced a "once removed" phenomenon in which they were introduced to more senior researchers by their peer mentors. Second, vertical peer mentorship can increase the quality of the available mentors over time by providing a platform through which emerging researchers can hone mentorship skills. Third, vertical peer mentorship can also 
increase the quantity of available mentors because positive mentorship experiences increase the willingness of early career individuals to provide mentorship themselves (McBride et al., 2019). Within our program many mentees either simultaneously or subsequently participated as mentors. Mentors in this program rated their satisfaction even slightly higher than mentees. The benefits of mentorship for mentors remain under-researched (Lundgren \& Orsillo, 2012). However, the relationships formed through this vertical peer mentorship program were perceived as mutually beneficial. Thus, there are distinct incentives to promoting programs that leverage the experience and expertise of slightly advanced peers to assist more junior colleagues.

Various elements of the program likely contributed to its effectiveness. First, providing a formal structure for pairing and fostering early career mentor-mentee dyads alone seemed to support success. The program was developed based on direct feedback from junior researchers within this organization. Therefore, providing a platform for easy access to mentorship was readily welcomed. Further, the system of closely matching mentor and mentee interests, skills, and desires for the program may have contributed to positive outcomes, as mentor-mentee similarities facilitate relationship satisfaction and collaboration (Holt et al., 2016). In particular, ensuring mentors' (in addition to mentees') goals were met appeared to attract highly productive, driven early career members to serve as mentors. Providing support and resources to scaffold and structure dyads' relationship was also helpful in preventing avoidable pitfalls. Because mentoring is often a new skill for early career professionals, many appreciated guidance on how to build an effective partnership. Soliciting regular program evaluation data was found to be crucial in adapting the format to meet the needs of the participants. This also may have increased the program acceptability, as participants had had an opportunity to shape the direction of the program. 
There is little research in the area of mentorship within the clinical sciences, and even less on peer mentorship (Forehand, 2008). Although initial outcomes are provided in this paper, these were descriptive data collected for program evaluation rather than research purposes. Further testing of this model, including through randomized, controlled trials, is needed to fully determine the efficacy of this approach. We believe the data in this paper provide pilot evidence to suggest the utility for more stringent tests of this program. Definitive information also is lacking about which elements of the program were helpful, or should be altered. This program was designed to be flexible, whereas other peer mentorship programs have embedded additional structural elements, including an application process to vet peer mentors and/or mentees, formal training of peer mentors/mentees, and ongoing mentorship of peer mentors by more senior individuals (Jacobs et al., 2015). Whereas other peer mentorship programs have included a group mentorship component (Lorenzetti et al., 2019), our program was encompassed by dyads. Such pairings may have limited opportunities to learn from a range of individuals. Indeed, mentorship dyads stated that they desired greater opportunities for connecting and networking.

There are some possible nuances of the eating disorders field that could necessitate alterations to this program if implemented by other groups. The eating disorders field is relatively small and interconnected, and historically also has been homogenous in demographic composition (Jennings Mathis et al., 2020). It may not be possible to dedicate as much effort to closely matching dyads' interests in a larger program, and simpler matching criteria or algorithms would be needed. Therefore, adaptations (e.g., more frequent monitoring from program leaders to ensure dyads are active) may have to be made to accommodate a larger, more expansive group. Smaller, more specialized programs may encounter problems with adequate supply of mentors to closely match based on individual preferences. In these cases, flexibility 
around mentorship goals may be needed (e.g., prioritizing professional development over content area mentorship). Given that the success and impact of mentorship programs has been found to vary according to demographic composition (Fleming et al., 2005; Yusoff et al., 2010), adaptations might be needed to optimize peer mentorship for a more diverse or underrepresented group in order to pair individuals with a mentor from a similar background who could provide guidance around navigating professional development barriers related to this identity (e.g., institutionalized racism). Future research is needed to determine the elements of vertical peer mentoring that promote the most auspicious outcomes across a range of participants and settings. It is notable, however, that many systems in the behavioral sciences are of a similar size and composition to the professional organization in which this program was developed and may be able to adopt this mentorship model without many structural changes.

The vertical mentorship program described herein could serve as a model for fostering the development of early career clinical researchers. This paper serves as one of the very few models available to guide the implementation of early career mentorship programs in the clinical sciences. As such, further evaluation of this program and its strategies is encouraged. The description of our vertical peer mentorship is intended to create a blueprint for a program that can be tested across disciplines. Not only is this manuscript designed as an outline for a successful program, it is also a call to action for the behavioral sciences to further consider creative ways to improve access to early career mentorship. Research evaluating the impact of such initiatives is critical to ensure that the development of future scientists is fostered according to the same rigor and empiricism employed in other academic endeavors. 


\section{References}

Akinla, O., Hagan, P., \& Atiomo, W. (2018). A systematic review of the literature describing the outcomes of near-peer mentoring programs for first year medical students. BMC Medical Education, 18, 98.

Allen, T. D., Eby, L. T., Poteet, M. L., Lentz, E., \& Lima, L. (2004). Career benefits associated with mentoring for protégeés: A meta-analysis. Journal of Applied Psychology, 89, $127-$ 136.

Andersen, T., \& Watkins, K. (2018). The value of peer mentorship as an educational strategy in nursing. Journal of Nursing Education, 57, 217-224.

Asgari, S., \& Carter, Jr., F. (2016). Peer mentors can improve academic performance: A quasiexperimental study of peer mentorship in introductory courses. Teaching of Psychology, $43,131-135$.

Bardone-Cone, A. (2018). Mentoring in clinical psychology. The Behavior Therapist, 4, 264267.

Benè, K. L., \& Bergus, G. (2014). When learners become teachers: A review of peer teaching in medical student education. Family Medicine, 46, 783-787.

Blau, F. D., Currie, J. M., Croson, R. T. A., \& Ginther, D. K. (2010). Can mentoring help female assistant professors? Interim results from a randomized trial. American Economic Review, $100,348-352$.

Burgess, A., van Diggele, C., \& Mellis, C. (2018). Mentorship in the health professions: A review. The Clinical Teacher, 15, 197-202.

Callahan, J. L., \& Watkins, C. E., Jr. (2018). Evidence-based training: The time has come. Training and Education in Professional Psychology, 12, 211-218. 
Clark, R. A., Harden, S. L., \& Johnson, W. B. (2000). Mentor relationships in clinical psychology doctoral training: Results of a national survey. Teaching of Psychology, 27, 262-268.

Eby, L. T., McManus, S. E., Simon, S. A., \& Russell, J. E. A. (2000). The protege's perspective regarding negative mentoring experiences: The development of a taxonomy. Journal of Vocational Behavior, 57, 1-21.

Efstathiou, J. A., Drumm, M. R., Paly, J. P., Lawton, D. M., O'Neill, R. M., Niemierko, A., et al. (2018). Long-term impact of a faculty mentoring program in academic medicine. PLoS One, 13, e0207634.

Fleming, M., House, S., Hanson, V. S., Yu, L., Garbutt, J., McGee, R., Kroenke, K., Abedin, Z., \& Rubio, D. M. (2013). The mentoring competency assessment: Validation of a new instrument to evaluate skills of research mentors. Academic Medicine, 88, 1002-1008.

Forbush, K. T., Crosby, R. D., Coniglio, K., \& Haynos, A. F. (2019). Education, dissemination, and the science of eating disorders: Reflections on the 2019 International Conference on Eating Disorders: Editorial to accompany IJED Virtual Issue in honor of the 2019 International Conference on Eating Disorders. International Journal of Eating Disorders, $52,493-496$.

Forehand, R. L. (2008). The art and science of mentoring in psychology: A necessary practice to ensure our future. American Psychologist, 63, 744-755.

Ghosha, R. \& Reio Jr., T. G. (2013). Career benefits associated with mentoring for mentors: A meta-analysis. Journal of Vocational Behavior, 83, 106-116.

Girves, J. E., Zepeda, Y., \& Gwathmey, J. K. (2005). Mentoring in a post-affirmative action world. Journal of Social Issues, 61, 449-479. 
Gruber, J., Borelli, J. L., Prinstein, M. J., Clark, L. A., Davila, J., Gee, D. G., et al. (2020). Best practices in research mentoring in clinical science. Journal of Abnormal Psychology, 129, $70-81$.

Hamrin, V., Weycer, A., Pachler, M., \& Fournier, D. (2006). Evaluation of peer-led support groups for graduate nursing students. Journal of Nursing Education, 45, 39-43.

Holt, D. T., Markova, G., Dhaenens, A. J., Marler, L. E., \& Heilmann, S. G. (2016). Formal or informal mentoring: What drives employees to seek informal mentors? Journal of Managerial Issues, 28, 67-82.

Irvine, S., Williams, B., \& McKenna, L. (2018). Near-peer teaching in undergraduate nurse education: An integrative review. Nurse Education Today, 70, 60-68.

Jackson V. A., Palepu, A., Szalacha, L., Caswell, C., Carr, P. L., \& Inui, T. (2003). "Having the right chemistry": A qualitative study of mentoring in academic medicine. Academic Medicine, 78, 328-34.

Jacobi, M. (1991). Mentoring and undergraduate academic success: A literature review. Review of Educational Research, 61, 505-532.

Jacobs, S., Atack, L., Ng, S., Haghiri-Vijeh, R., \& Dell’Elce, C. (2015). A peer mentorship program boosts student retention. Nursing, 45, 19-22.

Jennings Mathis, K., Anaya, C., Rambur, B., Bodell, L. P., Graham, A. K., Forney, K. J... Wildes, J. E. (2020). Workforce diversity in eating disorders: A multi-methods study. Western Journal of Nursing Research. doi: 10.1177/0193945920912396.

Kahn, S., Ginther, D. K. (2017). The impact of postdoctoral training on early careers in biomedicine. Nature Biotechnology, 35, 90-94. 
Keel, P. K., \& Smith, G. T. (2017). Introduction to the special section: Why we should highlight the outstanding contributions of young investigators in the field of eating disorders. Journal of Abnormal Psychology, 126, 479-480.

Kupfer, D. J., Schatzberg, A. F., Dunn, L. O., Schneider, A. K., Moore, T. L., \& DeRosier, M. (2016). Career Development Institute with enhanced mentoring: A revisit. Academic Psychiatry, 40, 424-428.

Lee, A., Dennis, C., \& Campbell, P. (2007). Nature's guide for mentors. Nature, 447, 791.

Li, W., Aste, T., Caccioli, F., Livan, G. (2019). Early coauthorship with top scientists predicts success in academic careers. Nature Communications, 10, 5170.

Lorenzetti, D. L., Shipton, L., Nowell, L., Jacobsen, M., Lorenzetti L., Clancy, T. \& Paolucci, E. O. (2019). A systematic review of graduate student peer mentorship in academia. Mentoring \& Tutoring: Partnership in Learning, 27, 549-576.

Lundgren, J. D., \& Orsillo, S. M. (2012). The science and practice of mentoring in psychology doctoral training. Journal of Cognitive Psychotherapy, 26, 196-209.

Mallinckrodt, B., \& Gelso, C. J. (2002). Impact of research training environment and Holland personality type: A 15-year follow-up of research productivity. Journal of Counseling Psychology, 49, 60-70.

McBride, A. B., Campbell, J., \& Deming, K. (2018). Does having been mentored affect subsequent mentoring? Journal of Professional Nursing, 35, 156-161.

Mikkonen, K., Elo, S., Tuomikoski, A. M., \& Kääriäinen, M. (2016). Mentor experiences of international healthcare students' learning in a clinical environment: A systematic review. Nurse Education Today, 40, 87-94. 
Murray, S. B., Pila, E., Griffiths, S., \& Le Grange, D. (2017). When illness severity and research dollars do not align: are we overlooking eating disorders? World Psychiatry, 16, 321.

Strand, M., \& Bulik, C. M. (2018). Trends in female authorship in research papers on eating disorders: 20-year bibliometric study. BJPsych Open, 4, 39-46.

Thimbleby, H. (2013). Technology and the future of healthcare. Journal Public Health Research, 2, e28.

Warren, J. R. (2019). How much do you have to publish to get a job in a top sociology department? Or to get tenure? Trends over a generation. Sociological Science, 6, 172196.

Yusoff, M. S. B., Rahim, A. F. A., Noor, A. R., Yaacob, N. A., \& Hussin, Z. A. M. (2009). The BigSib students' peer group mentoring programme. Medical Education, 43, 1106.

Zerzan, J. T., Hess, R., Schur, E., Phillips, R. S., \& Rigotti, N. (2009). Making the most of mentors: a guide for mentees. Academic Medicine, 84, 140-144. 
Appendix A. Application for prospective mentees

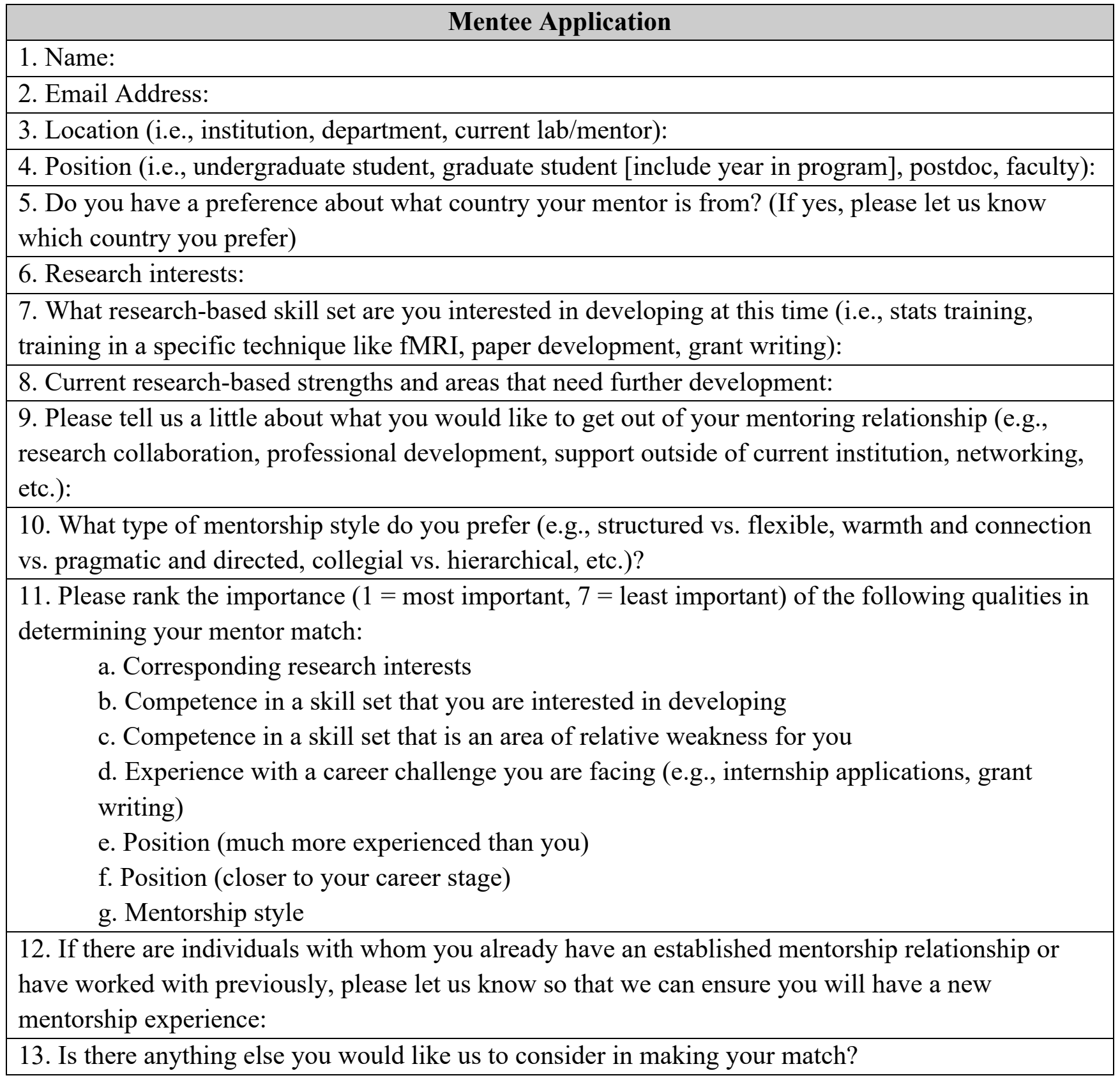


Appendix B. Application for prospective mentors

\begin{tabular}{|l|}
\hline \multicolumn{1}{|c|}{ Mentor Application } \\
\hline 1. Name: \\
\hline 2. Email Address: \\
\hline 3. Location (i.e., institution, department, lab): \\
\hline $\begin{array}{l}\text { 4. Position (i.e., undergraduate student, graduate student [indicate year in program], postdoc, faculty } \\
\text { [rank]): }\end{array}$ \\
\hline 5. Program of research/research interests: \\
\hline $\begin{array}{l}\text { 6. Areas in which you feel competent to provide mentorship (e.g., stats, specific skill like fMRI, } \\
\text { paper development, grant writing, professional development, grad school/internship applications) } \\
\text { and/or areas you wish to develop strengths in mentorship: }\end{array}$ \\
\hline 7. How would you describe your mentorship style (e.g., structured vs. flexible, warmth and \\
connection vs. pragmatic and directed, collegial vs. hierarchical, etc.)? \\
\hline $\begin{array}{l}\text { 8. What are your goals for participating as a mentor in the program (e.g., strengthen mentorship } \\
\text { skills, provide guidance for early career individuals, expand your professional network, etc.)? }\end{array}$ \\
\hline $\begin{array}{l}\text { 9. If you already act as a mentor in some capacity with mentee(s) who may participate in this } \\
\text { program, please let us know so that we can ensure you will be matched with a new mentee in order to } \\
\text { have a new mentorship experience: }\end{array}$ \\
\hline 10. Is there anything else you would like us to consider in making your match? \\
\hline
\end{tabular}


Appendix C. Program evaluation survey

\section{Mentor/Mentee Evaluation}

1. Did you contact your mentor/Were you contacted by your mentee?

2. Approximately how many times have you and your mentor/mentee been in contact?

3. At this point, do you have plans for continued contact with your mentor/mentee?

4. Did you identify goals for your relationship with your mentor/mentee?

5 . Which types of goals have you worked on with your mentor/mentee (check all that apply)?

a. General professional development goals

b. Grant-writing goals

c. Manuscript writing goals

d. Collaboration on one or more project(s)

e. Acquiring a specific set of technical skills (e.g., fMRI, programming, statistical analysis)

f. A specific application or interview process (e.g., grad school, internship, post-doc, faculty positions)

e. Other (list):

6. Have you and your mentor/mentee worked together or are you planning to work together on any of the following (check all that apply)?

a. Paper/manuscript

b. Grant

c. Abstract for conference/presentation

d. Other (list):

7. Did you use any of the mentorship materials saved in the Early Career SIG library to guide or structure your mentoring relationship?

If yes, how satisfied were you with these materials (1 [least satisfied] to 10 [most satisfied])?

If no, what prevented you from using these materials to guide your mentoring relationship? (check all that apply):

a. I did not know these materials were available

b. I forgot that these materials were available

c. I did not find these materials helpful

d. It felt too formal and/or structured to use these materials

e. We used a different format that I or my mentor found more useful

8. How satisfied are you with your experience with your mentor/mentee (1 [least satisfied] to 10 [most satisfied])?

9. How satisfied are you with the mentorship program overall (1 [least satisfied] to 10 [most satisfied])?

10. If you are willing, please explain your answer to the satisfaction questions above:

11. What suggestions do you have for improving this mentorship program based on your experience? Also, if there is anything you'd like us to know that was not addressed in the survey, please include that here as well. 
Table 1. Results of Academy for Eating Disorders Early Career Special Interest Group Vertical Peer Mentorship Program (20162020)

\begin{tabular}{|c|c|c|c|}
\hline \multirow[b]{2}{*}{ Variable } & \multicolumn{3}{|c|}{ M(SD)[Range] or $\%$} \\
\hline & Full sample $(n=109)$ & Mentees $(n=53)$ & Mentors $(n=56)$ \\
\hline Made contact ( $\%$ yes $)$ & 94.5 & 98.1 & 91.1 \\
\hline Meeting frequency (\# of meetings) & $7.67(8.78)[0-50]$ & $7.68(9.34)[0-50]$ & $7.67(8.43)[0-45]$ \\
\hline Plans for continued contact ( $\%$ yes) & 80.7 & 81.1 & 80.4 \\
\hline Identified mentorship goals ( $\%$ yes) & 82.6 & 83.0 & 80.4 \\
\hline General professional development goals & 77.5 & 79.5 & 75.6 \\
\hline Grant-writing goals & 20.0 & 23.1 & 19.5 \\
\hline Manuscript writing goals & 26.3 & 18.0 & 34.2 \\
\hline Collaboration goals & 16.3 & 12.8 & 19.5 \\
\hline Skill set acquisition goals & 6.3 & 5.1 & 7.3 \\
\hline Application/interview goals & 47.5 & 48.7 & 46.3 \\
\hline Other goals & 5.0 & 2.6 & 7.3 \\
\hline Collaborative work products ( $\%$ yes) & 30.3 & 33.9 & 26.8 \\
\hline Manuscript & 27.5 & 30.2 & 15.0 \\
\hline Grant & 3.7 & 5.7 & 1.8 \\
\hline Abstract & 3.7 & 3.6 & 3.6 \\
\hline Satisfaction with mentor/mentee (1-10) & $8.22(4.25)[1-10]$ & $7.97(2.67)[3-10]$ & $8.46(2.26)[1-10]$ \\
\hline Satisfaction with program (1-10) & $8.96(1.49)[2-10]$ & $8.61(1.76)[5-10]$ & $9.30(1.11)[2-10]$ \\
\hline
\end{tabular}

Note: Data were collected from the full sample on the variables: Made contact; Plans for continued contact; Identified mentorship goals, and Collaborative work products (\% yes). The rest of the variables were collected starting with the second cohort (2017-2018) and therefore have a sample size of $n=80$ (41 mentors, 39 mentees). 
Figure 1. Word clouds illustrating qualitative feedback from the Academy for Eating Disorders

Early Career Special Interest Group Vertical Peer Mentorship Program (2016-2020)
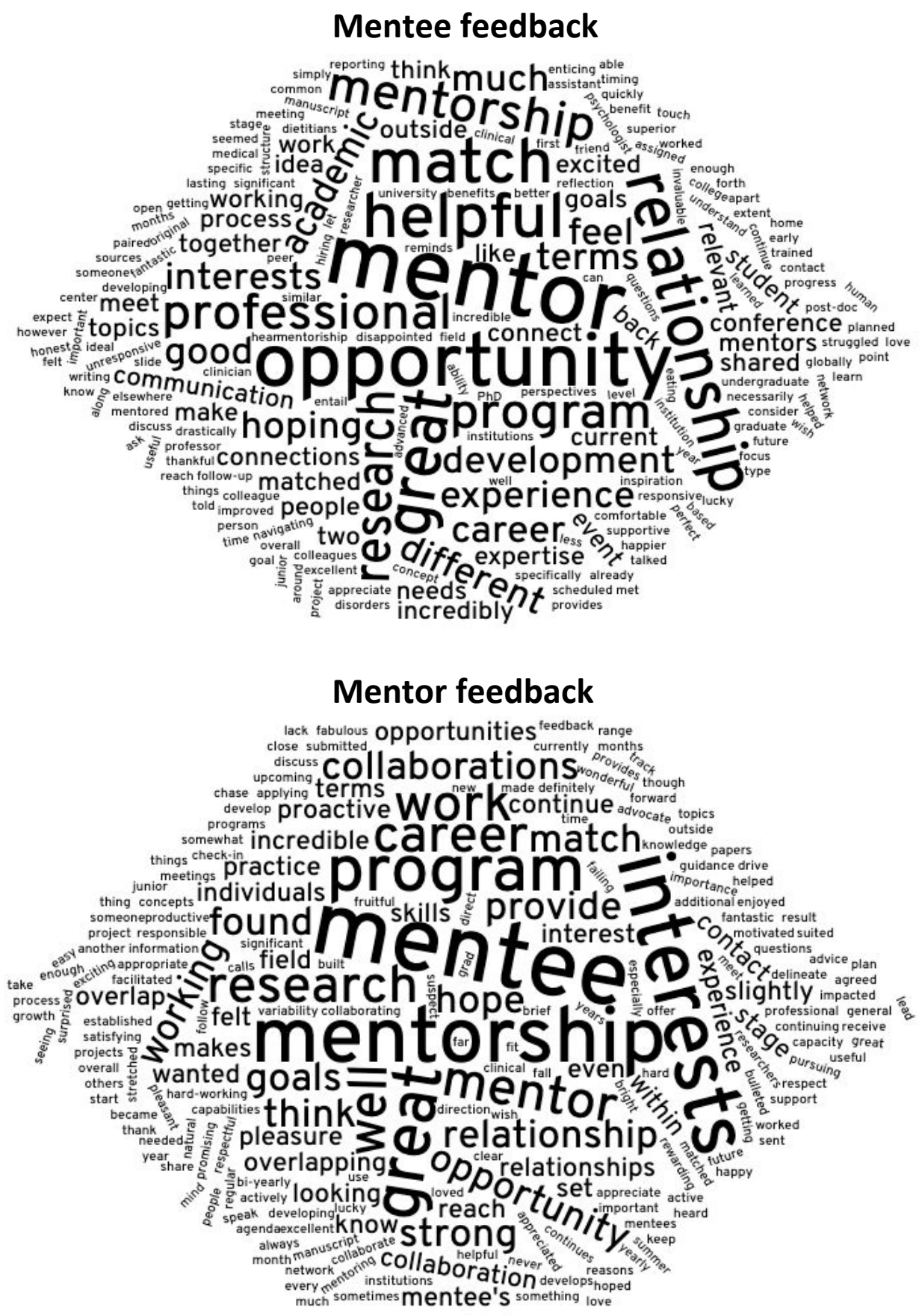

Note: Data derived from optional written feedback provided by mentees $(n=20)$ and mentors $(n$ $=23$ ). Common words have been (e.g., a, the) removed. 